UCRL-ID-129848

\title{
Sorption and Transport of Uranium on Hematite
}

\author{
B. E. Viani \\ P. C. Torretto
}

Febuary 3, 1998

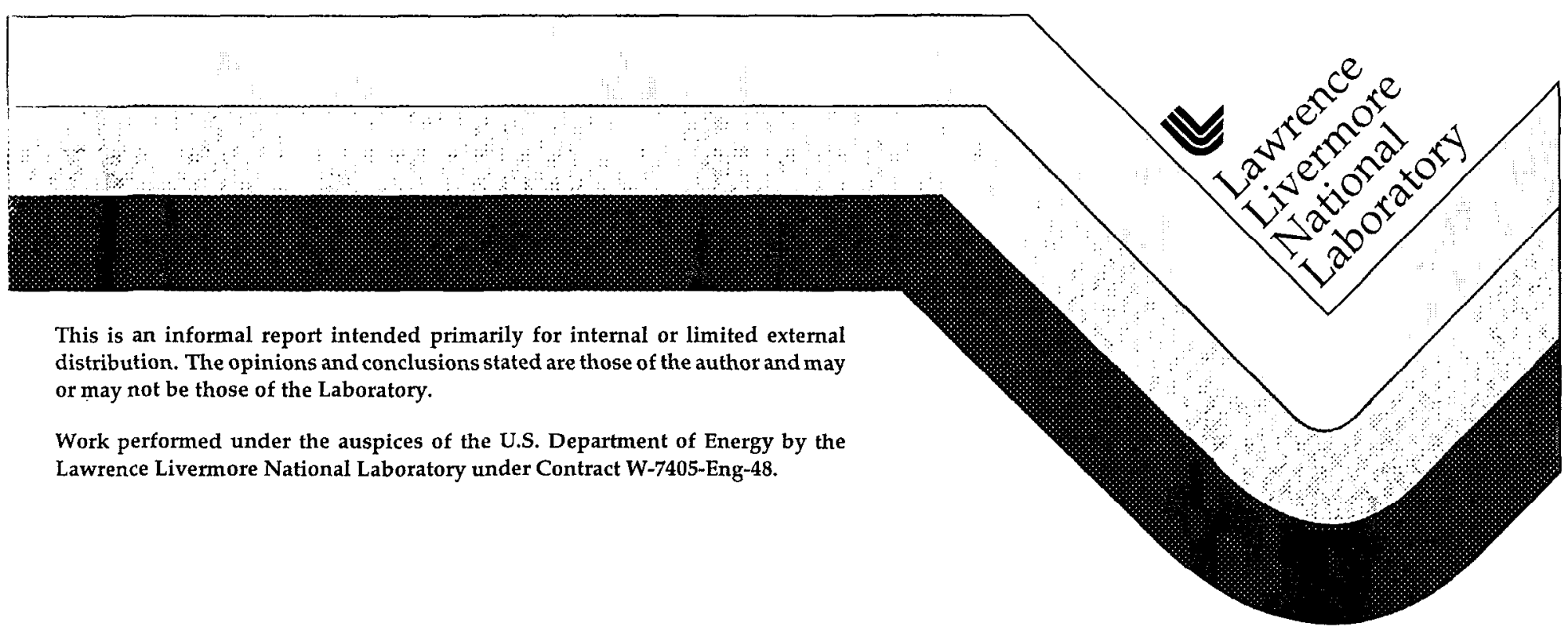




\section{DISCLAIMER}

This document was prepared as an account of work sponsored by an agency of the United States Government. Neither the United States Government nor the University of California nor any of their employees, makes any warranty, express or implied, or assumes any legal liability or responsibility for the accuracy, completeness, or usefulness of any information, apparatus, product, or process disclosed, or represents that its use would not infringe privately owned rights. Reference herein to any specific commercial product, process, or service by trade name, trademark, manufacturer, or otherwise, does not necessarily constitute or imply its endorsement, recommendation, or favoring by the United States Government or the University of California. The views and opinions of authors expressed herein do not necessarily state or reflect those of the United States Government or the University of California, and shall not be used for advertising or product endorsement purposes.

This report has been reproduced directly from the best available copy.

Available to DOE and DOE contractors from the Office of Scientific and Technical Information

P.O. Box 62, Oak Ridge, TN 37831

Prices available from (615) 576-8401, FTS 626-8401

Available to the public from the

National Technical Information Service

U.S. Department of Commerce

5285 Port Royal Rd.,

Springfield, VA 22161 


\title{
Sorption and Transport of Uranium on Hematite
}

\author{
Milestone SPL3BM4
}

B.E. Viani and P.C. Torretto

\section{INTRODUCTION}

Transport of radionuclides that escape failed waste packages (WP) may be significantly affected by interaction with the alteration products derived from the WP components and other construction materials. The interaction of WP's and other ferrous metal materials with groundwater prior to failure is expected to result in the formation of iron oxides (Viani, 1996). These phases are expected to significantly retard $U$ and $N p$, radionuclides that are not strongly retarded by the repository horizon and the surrounding rocks (Meijer, 1990). Because sorption of radionuclides onto iron oxides is strongly dependent on fluid composition (e.g.; $\mathrm{pH}$ and dissolved carbon), mechanistic models that capture the detailed chemistry and physics that control transport must validated before credible predictions of the effects of WP alteration products can be made, and before limits on radionuclide transport through the engineered barrier system (EBS) can be placed. Reactive transport models that couple sorption models to fluid flow models are also required to assess the ability of more simplistic PA models to capture the essential features of the transport process. This letter report presents results of sorption and transport experiments that are designed to obtain parameters to be used in coupled models and to test the ability of these models to predict transport.

\section{EXPERIMENTAL}

\section{MATERIALS}

Hematite was chosen to simulate the dominant corrosion product expected to form from a ferrous corrosion allowance layer on a waste package. Although less crystalline, more hydrous, and/or more reduced iron oxide phases (e.g.; ferrihydrite, goethite, magnetite) would almost certainly form during the corrosion process, these phases are likely to be transitory and would likely alter to hematite, the most stable phase thermodynamically under repository conditions (Viani, 1996). Hematite is thought to have a lower binding affinity for radionuclides than other Fe(III) oxides (Hsi and Langmuir, 1985), hence sorption and retardation data obtained with this mineral are expected to be conservative.

Synthetic hematite (Aldrich Chemical, $\mathrm{Fe}_{2} \mathrm{O}_{3},<5 \mu \mathrm{m}$ ) was used for sorption and transport experiments and verified by xray diffraction to be crystalline and free of contaminants. Nitrogen BET analysis yielded a specific surface of $1.5 \mathrm{~m}^{2} / \mathrm{g}$. Most natural Fe(III) oxides and synthetic oxides that have been used for sorption studies have specific surfaces far in excess of this value. Because the capacity for sorption is linearly related to specific surface, use of this well crystallized material is likely to provide a conservative estimate of the sorption capacity of a real corrosion layer. 
Quartz was used in the transport experiments as a dilutant so that breakthrough of the uranium tracer would be observable in a reasonable time period, and because surface complexation data for uranium adsorption on quartz were available (Turner, 1995). A relatively fine-grained natural quartz was used (Sigma Chemical, $\mathrm{SiO}_{2}, 0.5-10 \mu \mathrm{m}, 80 \%$ between 1-5 $\mu \mathrm{m}$ ) so that a homogenous mixture of quartz and hematite could be made without particle size segregation. In order to avoid clogging the exit filters of the column and transport of particulates from the column, the $<2 \mu \mathrm{m}$ fraction was removed from the quartz $(\sim 50 \%)$, prior to mixing it with hematite. The quartz was treated with $6 \mathrm{M} \mathrm{HCl}$ to remove trace metals and/or impurity phases. Xray diffraction analysis showed the treated quartz to be crystalline and frec of impurity phases.

\section{URANIUM ANALYSIS}

A stock solution of natural uranium spiked with $1 \%{ }^{233} \mathrm{U}$ was used to prepare the experimental uranium solutions for both the sorption and transport experiments. Prior to use, the uranium stock was purified from its thorium daughter products via column chromatography. Purity and concentration of the uranium stock was determined via liquid scintillation counting and UV-VIS spectrophotometry using NIST traceable uranium standards. Quantification of uranium in all experimental samples was done via alpha liquid scintillation spectroscopy using a Packard 2500TR/AB liquid scintillation counter. The counter was calibrated using the NIST traceable uranium stock solution and assuming $100 \%$ efficiency for the uranium alpha radiation. A value of $56,129,000 \mathrm{cpm}$ $\mathrm{U} / \mathrm{mmol} \mathrm{U}$ (or $1.7816 \mathrm{e}-8 \mathrm{mmol} \mathrm{U} / \mathrm{cpm} \mathrm{U}$ ) was determined for our counting and sample conditions. Samples were prepared by placing $2-3 \mathrm{~mL}$ assays into $18-20 \mathrm{~mL}$ of Ecolite scintillation cocktail. The samples were then counted for 30 minutes or until a $1 \% 2 \sigma$ uncertainty was achieved. The detection limit is on the order of $1 \times 10^{-8} \mathrm{~mol} / \mathrm{L}$. Uranium concentrations were then calculated as follows:

[U] $\mathrm{M}=\mathrm{U} \mathrm{cpm} / 56,129,000 / \mathrm{mL}$ of assay

\section{SORPTION EXPERIMENTS}

Hematite/solution mixtures having a mass/volume $(\mathrm{M} / \mathrm{V})$ ratio of $1 \mathrm{~g} / \mathrm{L}$ were equilibrated for 4 days at $26,38,50$, and $76^{\circ} \mathrm{C}$. The solutions were 0.01 molar in $\mathrm{NaCl}$ and $2 \times 10^{-6}$ molar in U(VI), with pH's varying between 4 and 10. Experimental samples were prepared by weighing $25 \mathrm{mg}$ of the hematite into $50-\mathrm{mL}$ polycarbonate Oakridge tubes and adding $25 \mathrm{~mL}$ of solution. The $\mathrm{pH}$ of the solutions was then adjusted to the desired $\mathrm{pH}$ using either $0.01 \mathrm{M} \mathrm{HCl}$ or $0.01 \mathrm{M} \mathrm{NaOH}$. All solutions were prepared $\mathrm{CO}_{2}$-free and the experiments were carried out in an argon atmosphere. Following equilibration in a constant temperature chamber, the final $\mathrm{pH}$ was measured on an aliquot of the supernatant. A $2.5-\mathrm{mL}$ aliquot of the supernatant was filtered through a $4.1 \mathrm{~nm}$ centrifugal filter and $2 \mathrm{~mL}$ of the filtrate was placed into a scintillation vial containing 20 $\mathrm{mL}$ of scintillation cocktail for uranium analysis. The concentration in the supernatant was used to compute the percent of the initial uranium sorbed by the hematite. 


\section{TRANSPORT EXPERIMENTS}

Solutions containing $2 \times 10^{-6}$ to $7.6 \times 10^{-6} \mathrm{~mol} / \mathrm{L}$ of U(VI), $1.33 \times 10^{-4} \mathrm{~mol} / \mathrm{L}$ of $\mathrm{NaI}$ and 0.01 $\mathrm{mol} / \mathrm{L}$ of $\mathrm{NaCl}$ having $\mathrm{pH}$ 's of 4.0, 5.0,6.0, and 8.0 were pumped through columns containing a mixture of quartz and hematite in the proportion of $94: 6$ by weight using a multichannel peristaltic pump. Fraction collectors were used to collect 75 drops per sample, which corresponded to volumes of 3.4 to $3.8 \mathrm{~mL}$ per sample for the 4 columns. The packed column length was $15 \mathrm{~cm}$ with an inside diameter of $1 \mathrm{~cm}$. The columns were filled by adding a slurry of the quartz:hematite mixture in deionized water. The fractional porosity of the packed column was estimated to be $\sim 0.4$, or $\sim 4.7 \mathrm{~mL}$. Flow rates were relatively constant within columns, but varied between columns from 2.2 to $3.3 \mathrm{~mL} / \mathrm{h}$.

Iodide was added to provide a conservative tracer by which to compare the relative retardation of $U$. Effluent samples were treated in the same manner as the sorption samples, except that a specific ion electrode was used to measure the concentration of iodide. Because breakthrough of uranium at pII 6 and 8 was not observed, it was decided to flush the $\mathrm{pH}-8$ column with untraced $0.01 \mathrm{M} \mathrm{NaCl}$ at $\mathrm{pH} 4$ and collect enough samples to observe breakthrough.

\section{MODELING}

A surface complexation model (SCM) was used to simulate both batch adsorption and flow experiments. Surface complexation models are complex and require a minimum of 4 to 8 parameters to characterize sorption. Dzombak and Morel (1990) and Turner (1995) showed that the diffuse double layer model (DLM), the simplest of the SCM's, is capable of effectively modeling a wide variety of metal-surface interactions. For each type of sorption site, equilibrium constants for 2 protonation reactions (acidity constants), the density of sites per unit surface area, and equilibrium binding constants for each sorbing species are required. In keeping with Dzombak and Morel's suggestion to standardize some of the parameters, we used previously published acidity constants and total site density that have been shown to be effective in modeling adsorption of radionuclides on iron oxides and other phases (Turner, 1995). We also followed Turner's lead in constraining the sorption of uranium to only one species. Thus, for a single type of site, only one parameter could be adjusted to fit the data. Though relatively simple, the DLM model contains features that allow for the effects of $\mathrm{pH}$, competing adsorption, and ionic strength on uranium adsorption. The DLM model requires equilibrium constants that quantify the following reactions:

$$
\begin{array}{lll}
>\mathrm{FeOH}^{\circ} \quad=\quad>\mathrm{FeO}^{-}+\mathrm{H}^{+} & \mathrm{K} \\
>\mathrm{FeOH}^{\circ}+\mathrm{H}^{+}=\quad>\mathrm{FeOH}_{2}^{+} & \mathrm{K}_{+} \\
>\mathrm{FeOH}^{0}+2 \mathrm{H}_{2} \mathrm{O}+\mathrm{UO}_{2}^{++}=\quad>\mathrm{FeOUO}_{2}(\mathrm{OH})_{2}^{-}+3 \mathrm{H}^{+} & \mathrm{K}_{\mathrm{B}}
\end{array}
$$

where $>\mathrm{FeOH}^{\circ}$ signifies the surface site, and $\mathrm{K}, \mathrm{K}_{+}$, and $\mathrm{K}_{\mathrm{B}}$ are the deprotonation, protonation, and binding constant, respectively. The effects of electrostatic interactions are explicitly provided for in the formulation of the surface binding equilibrium constants (Dzombak and Morel, 1990). 
The REACT geochemical modeling code (Bethke, 1994) that includes the DLM model, was used with the acidity constants and site densities shown in Table 1 to model the sorption data. The binding constant for uranium was varied until the simulation visually fit the data. REACT makes use of the latest LLNL thermodynamic database (GEMBOCHS) for solution and solid phases (Johnson and Lundeen, 1994).

Table 1. Parameters used for modeling sorption (DLM) and transport of uranium using REACT and X1t codes.

\begin{tabular}{|c|c|c|c|c|c|c|c|c|c|c|}
\hline \multirow[t]{2}{*}{ Phase } & \multirow[t]{2}{*}{$\begin{array}{l}\text { Vol. } \\
\%^{(1)}\end{array}$} & \multirow{2}{*}{$\begin{array}{l}\text { Specific } \\
\text { surface } \\
\mathrm{m}^{2} / \mathrm{g}\end{array}$} & \multirow{2}{*}{$\begin{array}{l}\text { Site density } \\
\text { sites } / \mathrm{nm}^{2}\end{array}$} & \multirow{2}{*}{$\begin{array}{l}\text { Fraction } \\
\text { strong } \\
\text { sites }\end{array}$} & \multirow{2}{*}{\multicolumn{2}{|c|}{$\begin{array}{c}\log \mathrm{K}_{+} \\
\mathrm{Wk}^{(2)} \text { Strng }\end{array}$}} & \multicolumn{2}{|c|}{$\log K$} & \multicolumn{2}{|c|}{$\log \mathrm{K}_{\mathrm{B}}$} \\
\hline & & & & & & & Wk & Strng & Wk & Strng \\
\hline Hematite & 1.9 & 1.50 & 2.31 & 0.0325 & 7.35 & 7.35 & -9.17 & -9.17 & -11.7 & -7.7 \\
\hline Quartz & 58.1 & 0.10 & 2.31 & 0.0 & $\mathrm{NA}^{(3)}$ & & -7 & 20 & & .45 \\
\hline
\end{tabular}

(1) Volume of mineral in column expressed as percent of total volume.

(2) $\mathrm{Wk}=$ weak site; Strng = strong site.

${ }^{\text {(3) }}$ Because the point of zero charge is so low for quartz $(\mathrm{pH} \sim 2)$, the protonation constant has not been defined nor is it needed to model this system.

A one-dimensional reactive transport code, X1t (Bethke, 1996), that simulates advective, diffusive, and dispersive transport while accounting for chemical changes due to precipitation dissolution, surface complexation (DLM), and solution speciation, was used to model the experimental data from the column studies. X1t simulations use the method of operator splitting by which the calculation of mass transfer is performed separately from the chemical aspects of the computation. For the simulations presented, the dispersivity was set to $0.15 \mathrm{~cm}$ and the number of nodes to 20 . The fraction of node length that the fluid traverses in one time step (Courant number) was set to 1.0, to limit numerical dispersion. The volumes, surface areas, and DLM parameters used in the simulations for the quartz and uranium components are shown in Table 1.

\section{RESULTS AND DISCUSSION}

\section{BATCH EXPERIMENTS}

Figure 1 shows the results of the batch sorption experiments at 4 temperatures. Increasing temperature has been shown to increase the binding of metals to mineral surfaces (Brady, 1994). The data in Figure 1 indicate that up to $50^{\circ} \mathrm{C}$ there is a slight increase in the binding of uranium at lower to neutral $\mathrm{pH}$ 's, but that there appears to be little effect on binding at neutral and higher $\mathrm{pH}$ 's.

Figure 2 shows the results of simulating sorption using REACT and a single-site DLM (weak site) using the parameters in Table 1 . The $\log \mathrm{K}_{\mathrm{B}}$ of the binding constant that best fit the data, -11.7 , is about $1.5 \log$ units smaller than that reported for goethite for the same adsorbed uranium species (Turner, 1995). Considering that site density and acidity 
constants are the same as used by Turner (1995), and assuming the measured specific surface is accurate and that the aqueous phase thermodynamic data used by Turner is similar to that in GEMBOCHS, the difference in $\log \mathrm{K}_{\mathrm{B}}$ 's can be ascribed to a lower affinity of the hematite surface for uranium compared to goethite. This is consistent with Hsi and Langmuir's (1985) conclusions. It should be noted that to use this binding constant in a simulation would require using the same acidity constants and aqueous thermodynamic data used in the simulations.

Because acidity constants for hematite at elevated temperatures were not available, the binding constant was not estimated at the higher temperatures. Experiments are planned to measure the effect of temperature on acidity constants so that uranium adsorption at higher temperatures can be modeled.

It has been observed that for some metals, a second surface site having a high affinity for the metal is necessary to describe sorption at very low loading or at low pH's (Dzombak and Morel, 1990). Typically, the necessity of a second site is identified by performing an isotherm experiment that extends the adsorbed loading to very low values. The high affinity site necessary to describe the isotherm is commonly only a fraction $<5 \%$ of the total adsorption sites. Figure 3 shows a REACT/DLM simulation for which $3.25 \%$ of the total sites are high affinity (strong sites) for which the $\log \mathrm{K}_{\mathrm{B}}$ is -7.7. The fraction of strong sites was inferred from the breakthrough data for the $\mathrm{pH}-4$ transport experiment as shown below. It is important to note that the inclusion of the second site does not significantly change the visual fit of the simulation to the data, and that the effect of the second site on the fit is most evident at the lowest pH's.

\section{TRANSPORT EXPERIMENTS}

Figure 4 shows the concentrations of iodide and uranium measured in the effluent for the four columns. Breakthrough of iodide was rapid (approximately 1 pore-volume) and breakthrough of uranium was significantly delayed relative to iodide. The shape of the uranium breakthrough for the $\mathrm{pH}-4$ and $\mathrm{pH}-5$ experiments was quite sharp. After approximately $416 \mathrm{~mL}$ of the uranium-bearing pH-8 influent had been passed through the column, the influent was changed to a tracer-free solution at $\mathrm{pH} 4$. The concentrations of iodide and uranium subsequent to the change in influent are shown in Figure 5. Breakthrough was observed at almost the same effluent volume observed for the $\mathrm{pH}-4$ column. Approximately $5 \%$ of the uranium input into the column was desorbed by the time the experiment was stopped.

Simulating uranium breakthrough using the single-site DLM parameters derived from the sorption experiments resulted in a predicted breakthrough earlier than observed (Figure 6). If the binding constant for uranium was made larger, the breakthrough point could be matched, but the breakthrough was much less sharp, occurring over $40-60 \mathrm{~mL}$ rather than $\sim 15$.

To test the effect of a high affinity site, the simulation was rerun including a site with a binding constant 4 orders of magnitude greater than the binding site deduced from the sorption results. This binding constant is large, but is in line with strong site binding 
constants reported for transition metals on iron oxides, which vary between 3 and 4 orders of magnitude larger than the corresponding weak site binding constants (Dzombak and Morel, 1990). The simulated breakthrough was very sensitive to the fraction of strong sites included in the model; thus the fraction of strong sites could be estimated with precision. Including the strong binding site was the only means to match the breakthrough point and the shape of the experimental breakthrough curve (Figure 6). Although this match does not prove the presence of such a site, it is apparent that batch sorption data that does not address the presence of high affinity sites may not provide appropriate parameters for modeling transport; the transport experiments apparently may provide a quite sensitive test for the presence of a small quantity of high affinity sites. These results may mean that a simplified adsorption parameter set (Turner; 1995) may not be sufficient to accurately model transport.

In Figure 7, the experimental results for the entire pH-8 column experiment (both initial loading at $\mathrm{pH} 8$ and desorption at $\mathrm{pH} 4$ ) are compared to the simulation prediction using the two-site model for hematite described above. As expected, the simulation correctly predicts the breakthrough of the iodide, but it predicts earlier breakthrough of the uranium, and also predicts the uranium peak concentration to be much larger. The simulation predicts almost all of the uranium to be desorbed within the first $50 \mathrm{~mL}$ following breakthrough in contrast to the approximately $5 \%$ observed in the experiment.

For the X1t simulations shown, precipitation of any supersaturated phases was not allowed. If it is assumed that quartz solubility controls the level of silica in solution, the model predicts that the solution would become supersaturated with respect to the uranium silicate phase, soddyite. It is possible that precipitation of a uranium silicate occurred in the column during the passage of the $\mathrm{pH}-8$ solution. If so, a precipitate might not necessarily dissolve rapidly enough to be eluted by the subsequent $\mathrm{pH}-4$ fluid.

It is clear that a variety of factors play a role in the transport of uranium through even a very simple system such as the quartz/hematite mixture. The simulations pointed out some changes that could be made to the experimental protocol to simplify the interpretation of the results.

1. The specific surface area and batch sorption data for the quartz used in the experiment must be measured rather than estimated. It may be that sorption on quartz is playing a larger role than thought, if for example, its specific surface was significantly larger than $0.10 \mathrm{~m}^{2} / \mathrm{g}$.

2. The quartz/hematite mixture should be conditioned to the $\mathrm{pH}$ of the influent solution prior to filling the column. This would minimize $\mathrm{pH}$ excursions that were observed, and that were predicted by the modeling.

3. The concentration of uranium in the higher $\mathrm{pH}$ solutions will need to be reduced to avoid supersaturating with respect uranium silicate phases. The effluent solutions will need to be analyzed for silica as well as uranium and the column material analyzed for uranium-bearing solid phases. 
4. The presence of high affinity sites may need to be independently measured using an adsorption isotherm approach.

5. Carbonate will need to be added to the influent solutions both to assess its role in transport and for providing a means of obtaining uranium breakthrough for transport experiments at neutral and higher $\mathrm{pH}$ 's.

\section{REFERENCES}

Bethke, C.M. 1994. A Users Guide to Rxn, Act2, Tact, React, and Gtplot. Copyright Craig M. Bethke, University of Illinois, Champaign, IL.

Bethke, C.M. 1996. Reactive Transport and Basin Modeling. Short Course Workbook. Hydrogeology Program, University of Illinois, Champaign, IL May 29-31, 1996.

Brady, P.V. 1994. Alumina surface chemistry at 25,40 , and $60^{\circ} \mathrm{C}$. Geochim. Cosmochim. Acta. 58:1213-1217.

Dzombak, D.A., and Morel, F.M. 1990. Surface Complexation Modeling: Hydrous Ferric Oxide. Wiley, New York.

Hsi, C-K.D., and Langmuir, D. 1985. Adsorption of uranyl onto ferric oxyhydroxides: Application of the surface complexation site-binding model. Geochim. Cosmochim. Acta 49:1931-1941.

Johnson, J., and Lundeen, S. 1994. GEMBOCHS Thermodynamic Datafiles For Use With the EQ3/6 Software Package. Yucca Mountain Project Milestone Report M0L72.

Meijer, A. 1990. A strategy for the derivation and use of sorption coefficients in performance assessment calculations for the Yucca Mountain site. Pg. 9-40. Proceeding of the DOE/Yucca Mountain Site Characterization Project Radionuclide Adsorption Workshop at Los Alamos Laboratory. LA-12325-C.(NNA.19930629.0011)

Turner, D.R. 1995. A Uniform Approach to Surface Complexation Modeling of Radionuclide Sorption. Center for Nuclear Waste Regulatory Analyses, San Antonio, TX CNWRA 95-001.

Viani, B.E. 1996. Materials To Be Used For Radionuclide Transport Experiments. YMP Milestone SPL3A1M4. 

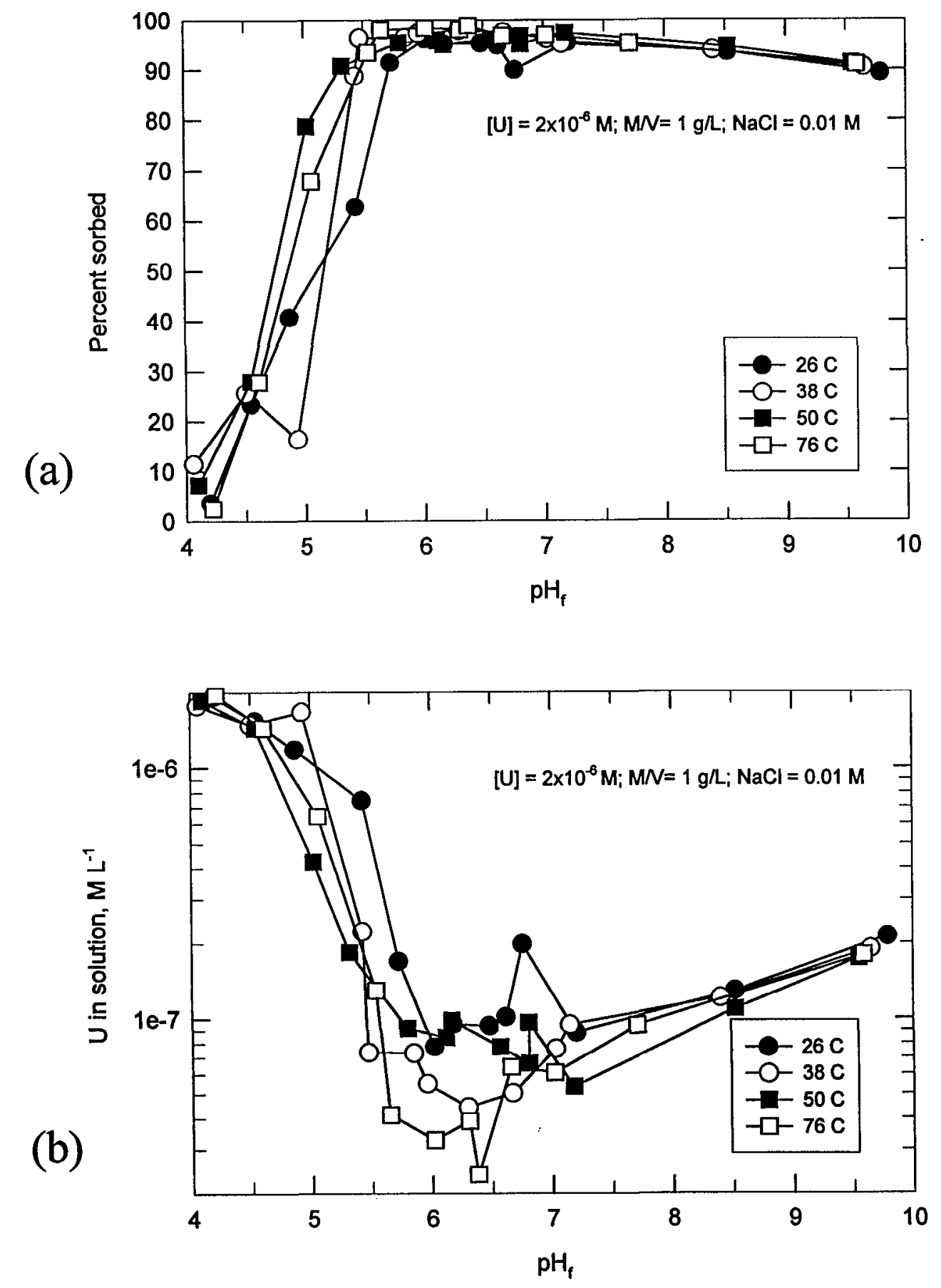

Figure 1. Variation in (a) percent sorbed and, (b) concentration of $U$ in solution vs. final $\mathrm{pH}$ in 4-day batch experiments. $\mathrm{U}=1 \times 10^{-6} \mathrm{M} ; \mathrm{M} / \mathrm{V}$ of hematite $=1 \mathrm{~g} / \mathrm{L}$; background electrolyte $=0.01 \mathrm{M} \mathrm{NaCl}$. 
(a)

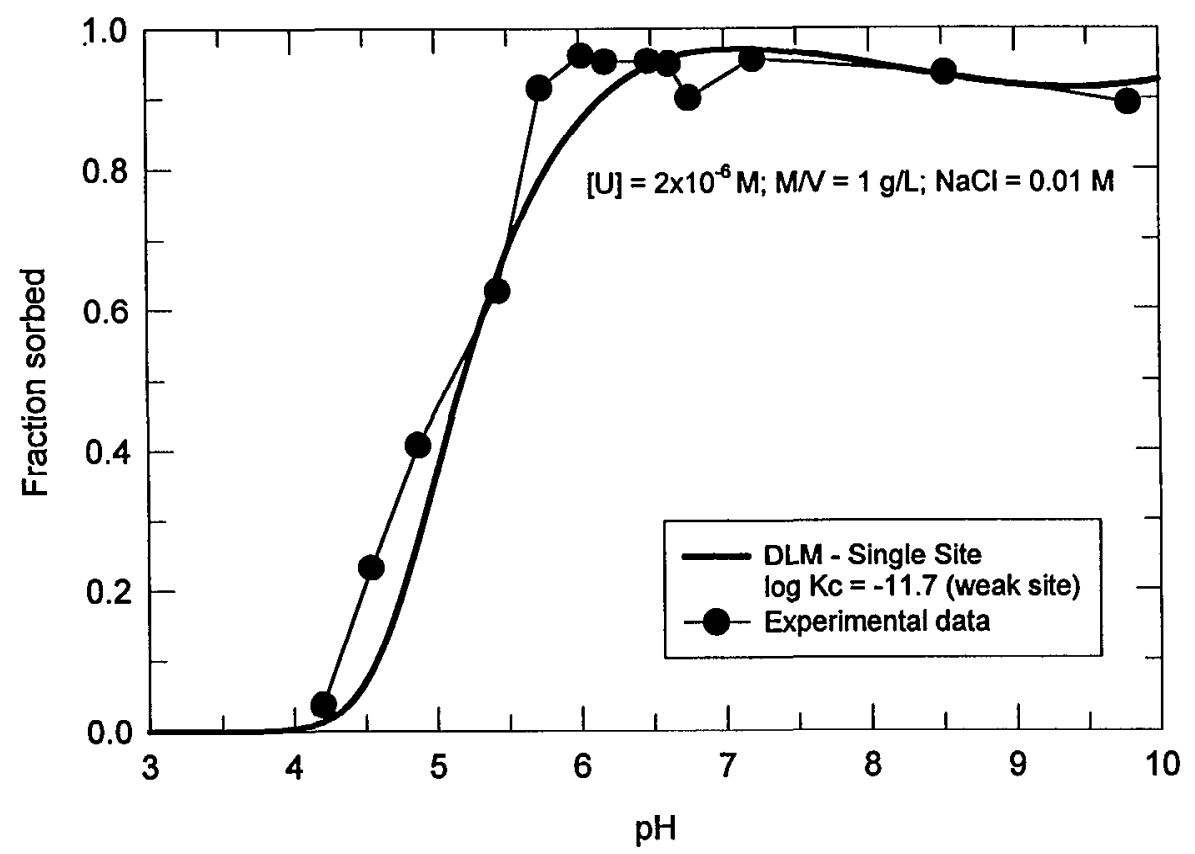

(b)

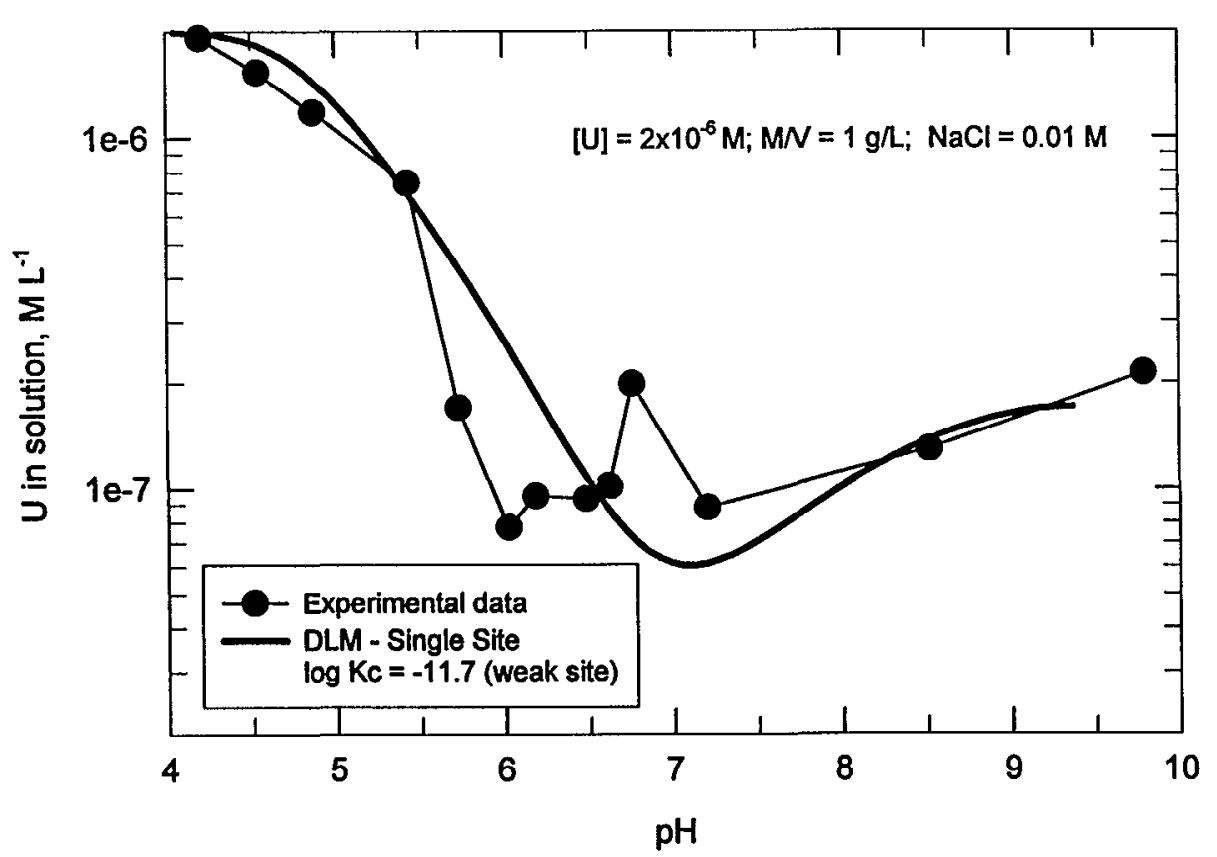

Figure 2. Comparison of DLM model (single-site) prediction of (a) fraction of $U$ sorbed, and (b) concentration of $U$ in solution with experimental results at $26^{\circ} \mathrm{C}$. Model parameters used are listed in Table 1. 
(a)

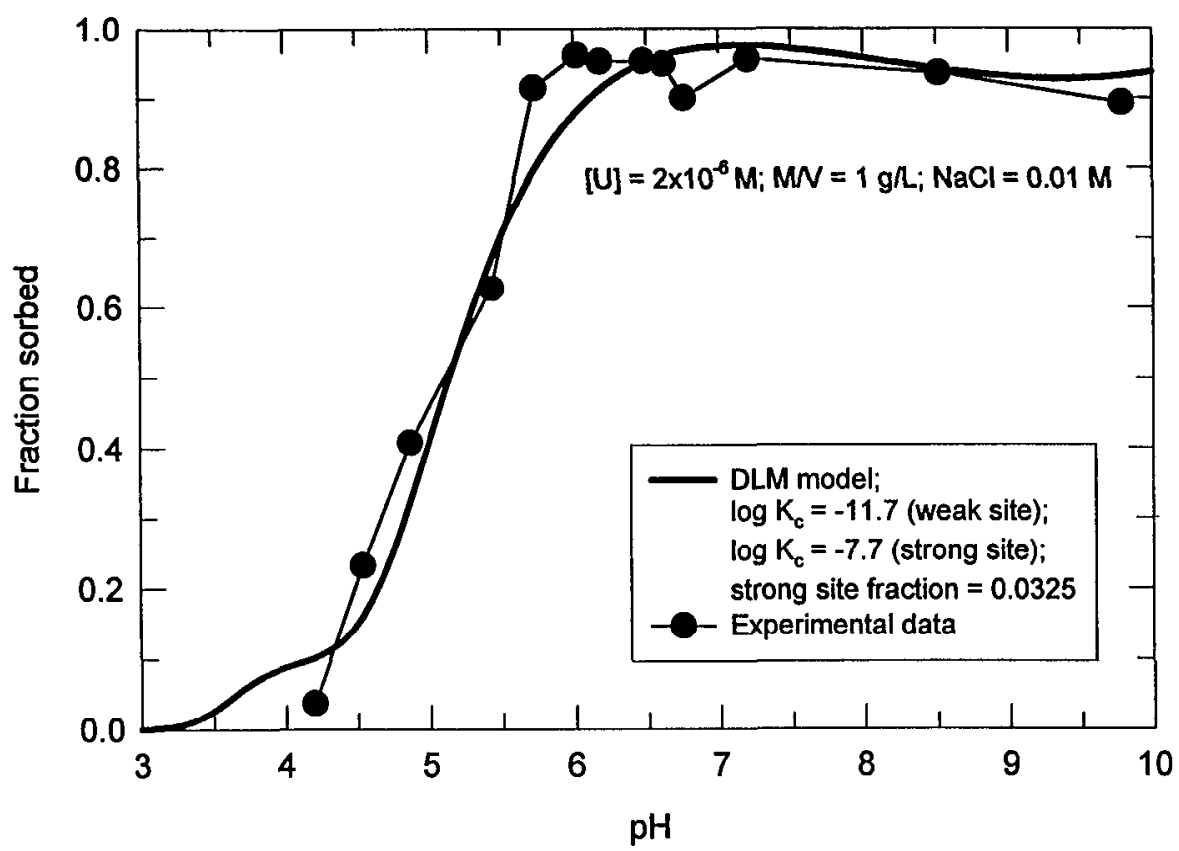

(b)

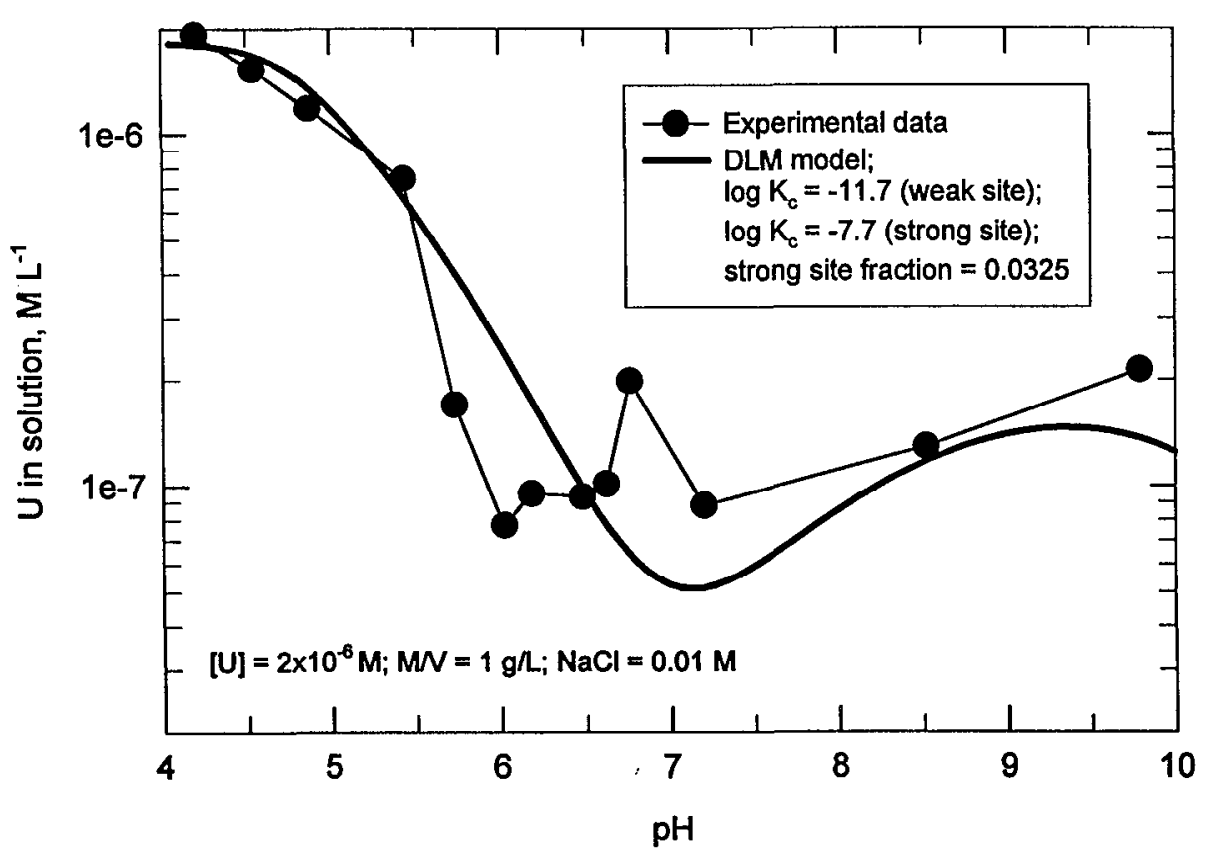

Figure 3. Comparison of DLM model (two-site) prediction of (a) fraction of U sorbed, and (b) concentration of $U$ in solution with experimental results at $26^{\circ} \mathrm{C}$. Model parameters used are listed in Table 1. 


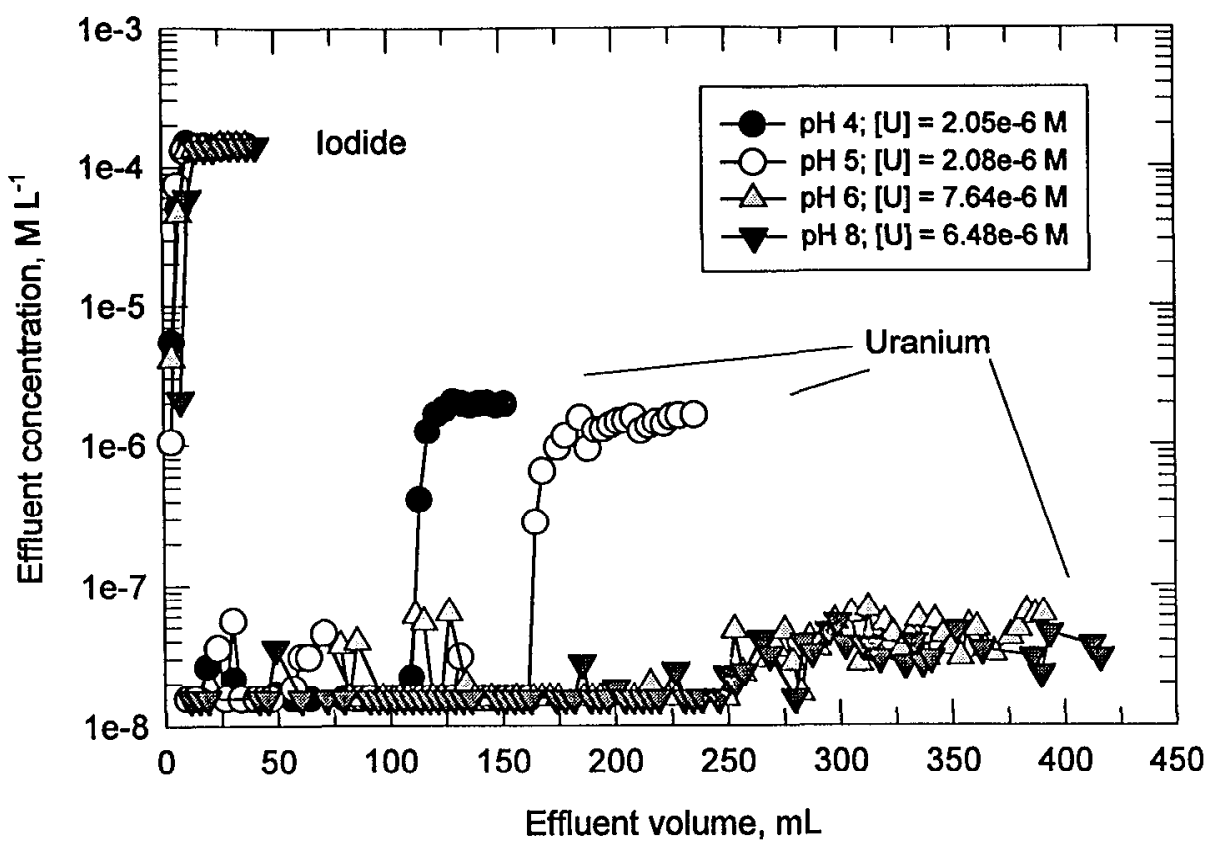

Figure 4. Variation in concentration of $\mathrm{I}^{-}$and $\mathrm{U}$ vs. volume of effluent at $26^{\circ} \mathrm{C}$ for hematite:quartz columns at four $\mathrm{pH}$ 's.

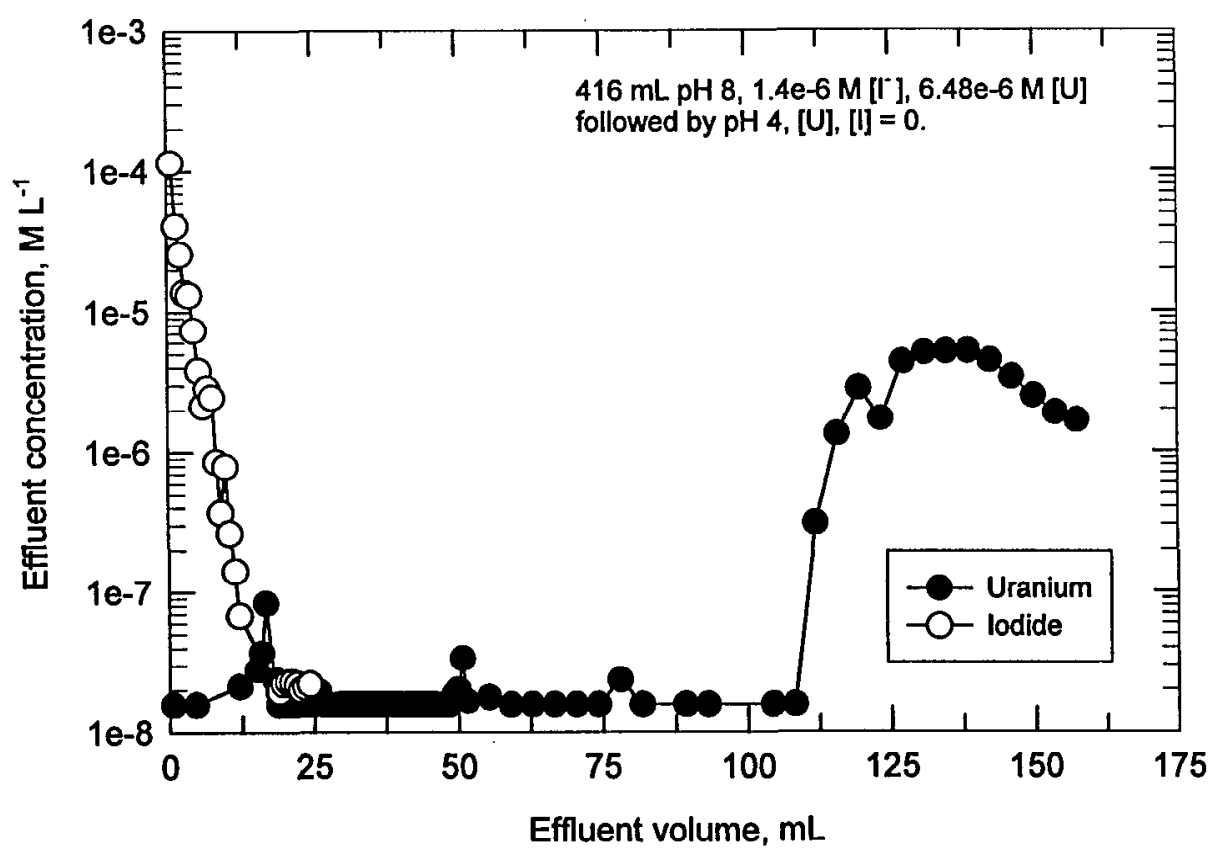

Figure 5. Variation in concentration of $\mathrm{I}^{-}$and $\mathrm{U}$ vs. volume of effluent in $\mathrm{pH}-8$ column subsequent to the input of $\mathrm{pH}-4$ tracer-free solution. 


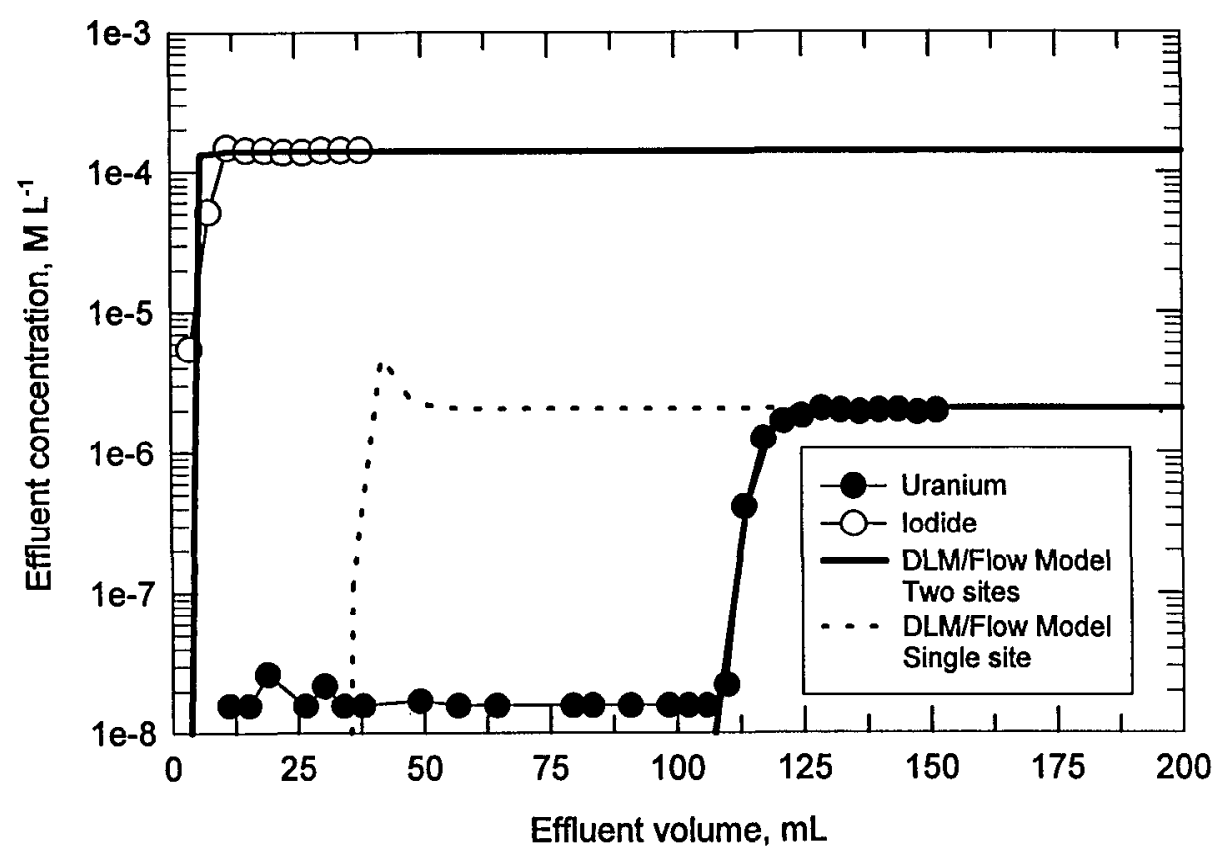

Figure 6. Comparison of X1t transport model (single and two-site DLM) vs. observed $\mathrm{I}^{-}$ and $\mathrm{U}$ concentrations in cffluent from $\mathrm{pH}-4$ column.

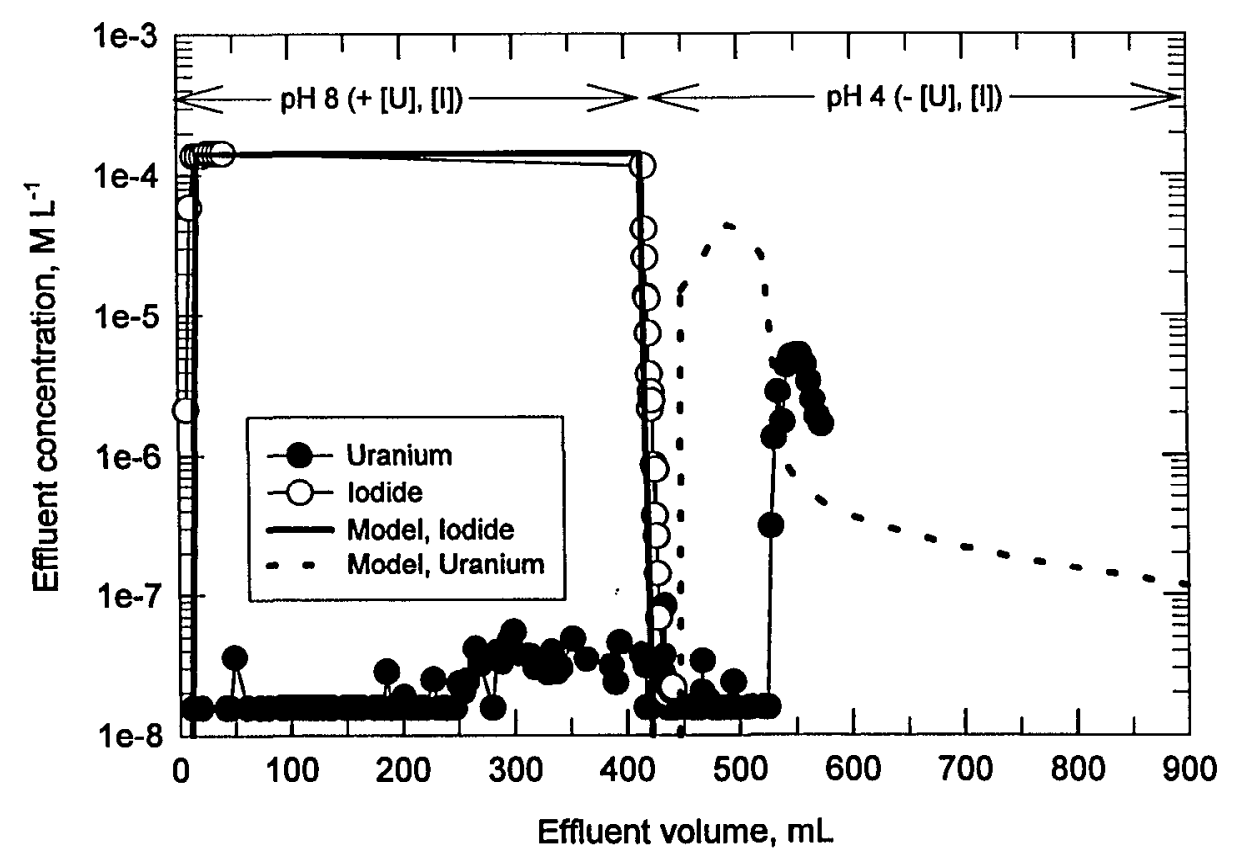

Figure 7. Comparison of X1t transport model (two-site DLM) vs. observed $\mathrm{I}^{-}$and $\mathrm{U}$ concentrations in effluent from $\mathrm{pH}-8$ column. 


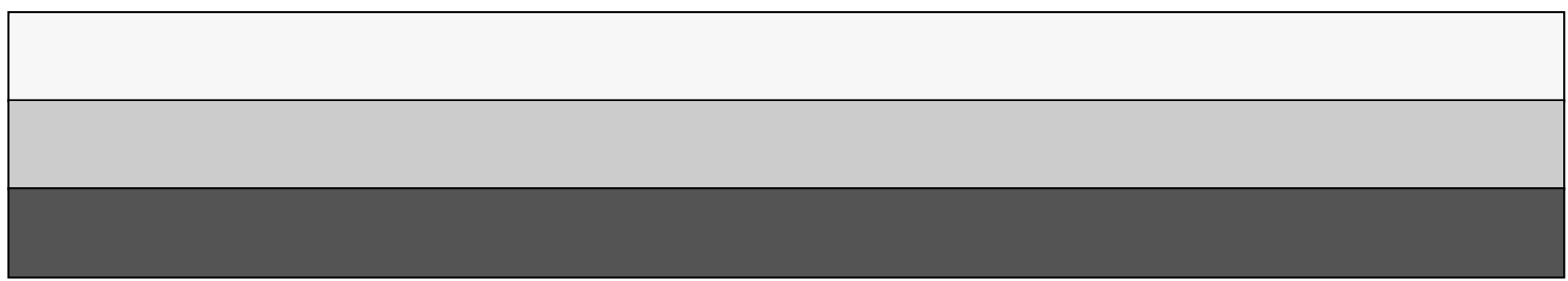

